\title{
CONDIÇÃO: SOCIEDADE, EFICÁCIA E SENTIDO NO PENSAMENTO DE ERIC WEIL
}

\author{
Daniel Benevides Soares ${ }^{1}$
}

\begin{abstract}
Resumo:
A categoria da condição é a da ciência moderna marcada pela eficácia técnica. Essa ciência oferece a matriz para outras posteriores, como as ciências sociais. Por meio destas é que se apresenta a sociedade moderna na sua autocompreensão. Contudo, essa autocompreensão não significa uma compreensão sobre a questão do sentido. Com o fito de elaborar esse esquema, o presente artigo apresenta três momentos. No primeiro, traçamos o pano de fundo da discussão com a exposição das características da sociedade moderna, bem como o papel da eficácia técnica no seu bojo. No segundo, passamos ao tratamento da categoria da condição, privilegiando sua concepção de ciência, de modo a situarmos a sua limitação quanto ao tratamento da compreensão do sentido. Finalmente, no terceiro momento, identificamos de que maneira se dá o adequado espaço da compreensão da demanda pelo sentido, como uma questão eminentemente filosófica. Não se trata, é importante explicitar de imediato, de propor uma rejeição dos benefícios da técnica moderna. Entretanto, é importante reconhecer sua especificidade e as limitações que a ciência tecnicamente eficaz enfrenta ao deparar-se com questões que ultrapassam seus objetos e chamar atenção para a importância do papel da filosofia como uma das possibilidades humanas que se levanta contra aquela que constitui o seu problema fundamental: a violência.
\end{abstract}

Palavras-chave: Condição. Sociedade. Ciência. sentido.

\section{CONDICTION: SOCIETY, EFFECTIVENESS AND MEANING IN ERIC WEIL'S THOUGHT}

\begin{abstract}
:
The category of the condition is that of modern science marked by technical effectiveness. This science offers the matrix for others, such as the social sciences. It is through the social sciences that modern society presents itself in its self-understanding. However, this self-understanding does not mean an understanding of the question of sense. In order to elaborate this scheme, this article presents three moments. In the first, we trace the background of the discussion with the exposure of the characteristics of modern society, as well as the role of technical efficiency within it. In the second, we move on to the treatment of the condition category, privileging its conception of science, in order to understand its limitation regarding the treatment of understanding the sense. In the third moment, we identified how the adequate space for understanding the demand for sense is given, as an eminently philosophical issue. We do not propose a rejection of modern science. However, it is important to recognize its specificity and the limitations that technically effective science faces when faced with issues that go beyond its objects and draw attention to the importance of the role of philosophy as one of the human possibilities that arises against that which constitutes its fundamental problem: violence.
\end{abstract}

Keywords: Condition. Society. Science. Sense.

\footnotetext{
1 Doutor em Filosofia pela Universidade Federal do Ceará e professor da Faculdade Católica de Fortaleza. E-mail: benevides.soares@gmail.com.
} 


\title{
I. A autocompreensão da sociedade moderna.
}

É uma das citações mais conhecidas do pensamento de Eric Weil sua definição de sociedade moderna:

\begin{abstract}
[...] a sociedade moderna mostra-se calculista: toda decisão, toda transformação dos processos de trabalho e de organização, todo uso das forças disponíveis (humanas e naturais) deve ser justificado demonstrando que o domínio do homem sobre a matéria é reforçado, dito de outro modo, que o mesmo resultado mensurável é obtido com menor dispêndio de energia humana, ou que uma quantidade maior de forças naturais é posta à disposição da humanidade (ou da comunidade particular), o que não seria possível com métodos anteriores. A sociedade moderna é materialista porque nas suas decisões só os fatores materiais são levados em consideração. Ela é mecanicista porque todo problema deve ser transformado em problema de método de trabalho e de organização, e só deve referir-se ao mecanismo do trabalho social: todo problema que não pode ser formulado assim é, por definição, um falso problema².
\end{abstract}

Essa definição se dá a quem a observa como a sua autoconsciência, o que significa dizer que é assim que a sociedade moderna se apresenta segundo a consciência que é ditada por aqueles que emitem juízos de autoridade sobre ela ${ }^{3}$. Desse modo, será por estar baseada em teorias e convicções dessa ordem que a sociedade moderna é assim descrita. Esse é o aspecto exclusivo da sociedade que as ciências sociais descrevem adequadamente $^{4}$. Nela se verifica também um aspecto universal: os valores teóricos e práticos da ciência moderna e da tecnologia científica e a formação das estruturas da economia e ordenamento funcional das coletividades voltadas para o bem-estar material da humanidade ${ }^{5}$. A sociedade moderna, portanto, é aquela da hegemonia da técnica, da ciência, do cálculo, da matéria e do mecanismo. Como consequência dessa apresentação, podemos dizer também que a agressividade do trabalho e a racionalidade de sua organização definem a sociedade moderna ${ }^{6}$.

Mas o que, em primeiro lugar, podemos entender como sociedade na concepção weiliana? Para o filósofo, esse termo diz respeito à organização do trabalho social, expressão que, por sua vez indica a organização de uma comunidade histórica na sua luta contra a natureza exterior, violência primeira. A essa definição, acrescentemos ainda: a humanidade trabalhando em comunicação por meio da linguagem para o enfrentamento dessa violência. Depreendemos então que as formas de trabalho se

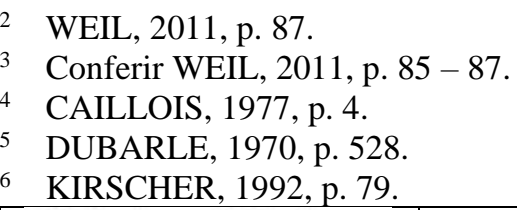

\begin{tabular}{|l|l|l|l|l|}
\hline Q Povista Dialectus & Ano 9 & n. 19 & Agosto-Dezembro 2020 & p. 38-50 \\
\hline
\end{tabular}


especificam em função das formas de linguagem. Isso também ocasiona a distinção entre tipos de sociedade ${ }^{7}$. Temos, portanto, sociedades que são modernas e aquelas que lhe antecedem: as de tipo mágico-religioso. Antes de passarmos ao tratamento das diferenças entre ambos os modelos de sociedade, é necessário uma palavra sobre a violência primeira.

Nunca é demais, em se tratando de um estudo respeitante à filosofia weiliana, pontuar que nos quadros do pensamento desse autor, a violência é o problema constitutivo da filosofia ${ }^{8}$ e que ela se dá como uma espécie de Proteu ${ }^{9}$, sob múltiplas formas ${ }^{10}$. No que diz respeito à violência exterior, esse conceito abrange aquela que o ser humano sofre de fora, como a fome, as doenças e a morte ${ }^{11}$. Dela é dita violência primeira, pois as demais, tais como a paixão, as tentações, a violência do ser humano contra o seu semelhante, encontram na violência natural o seu fundamento. Cumpre dizer ainda que a luta contra a violência da natureza é do grupo organizado, a sociedade, não do indivíduo. O ser humano enquanto espécie sobrevive em qualquer clima, porém, não o indivíduo isolado ${ }^{12}$. O modo como uma comunidade humana se organiza para enfrentar a violência da natureza exterior é o que delimita uma sociedade antiga, mágico-religiosa, em relação a uma moderna.

A sociedade moderna se entende como enfrentando uma natureza exterior hostil; trata-se, portanto, de uma luta contra uma realidade outra. Já a sociedade mágicoreligiosa não tem um outro que lhe seja exterior, pois toma a si mesma enquanto partícipe de um mundo cuja ordem ela assegura pela observação ativa e rigorosa dos ritos sem os quais a vida seria impossível ${ }^{13}$. Como se percebe em uma relação de pertença à natureza, a sociedade primitiva mágico-religiosa integra a vida humana em um mundo pleno de sentido. A sociedade moderna, por sua vez, exclui toda expressão de subjetividade individual, caracterizando-se pela qualidade entre sujeito agente versus um universo de objetos à sua disposição. A natureza exterior não é mais percebida sob categorias metafísicas que testemunham respeito e cujo curso seria impiedade perturbar: cosmos, belo, divino. Para essa sociedade, somente o trabalho constantemente mais eficaz é

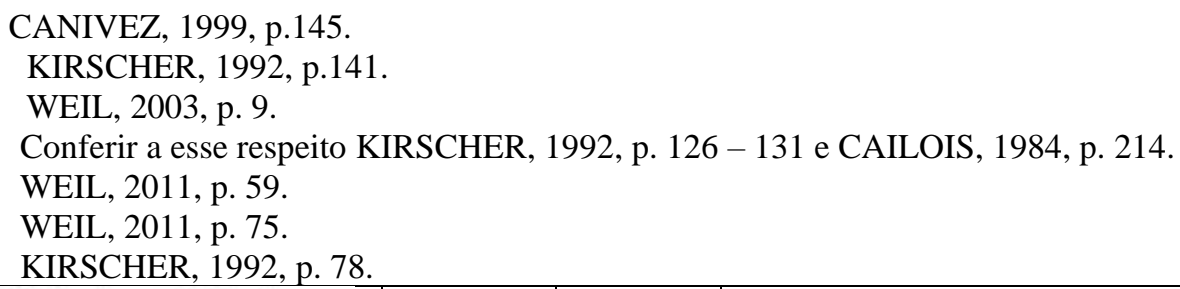

\begin{tabular}{|l|l|l|l|l|}
\hline Q Rovista Dialectus & Ano 9 & n. 19 & Agosto-Dezembro 2020 & p. $38-50$
\end{tabular}


trabalho verdadeiro ${ }^{14}$. Numa sociedade tradicional a linguagem possui uma função de transmissão, de saberes e ritos, de técnicas e modos de organização que não mudam ou que mudam pouco. A luta contra a violência da natureza que acomete o ser humano na forma do clima, das catástrofes, da necessidade é defensiva, estática ${ }^{15}$.

Essa mudança de paradigma na maneira de encarar a natureza localiza-se de modo geral e de forma esporádica na Europa no seio de nações diversas. Um traço importantíssimo dessa mudança é a ciência que se constrói com base no modo de encara a natureza como outro. A ciência moderna aparece ao longo do século XVII, acompanhada pela tecnologia mas não sem alguma lentidão. É apenas a partir de 1780 que a industrialização de tipo moderno começou, expandindo-se pouco a pouco ao mesmo tempo em que a competição entre as nações engaja-as individualmente e no seu conjunto nos processos históricos dos séculos XIX e XX. Entretanto, deve se frisar que, se as sociedades atualmente são fortemente industriais, elas permanecem em grande parte sociedades nacionais ${ }^{16}$. A sociedade moderna, portanto, é aquela na qual o ser humano se encontra atualmente e que se caracteriza essencialmente por sua luta contra a natureza exterior. Para ela, apenas a eficácia conta e tudo que não diz respeito à organização do trabalho social e não favorece essa eficiência é considerado como um fator desprovido de interesse para manutenção dessa organização ${ }^{17}$. O trabalho na sociedade moderna fundamenta a sua concepção na linguagem do cálculo racional. Aqui, ao contrário das sociedades mágico-religiosas, a luta contra a natureza é ofensiva e progressiva, pois se trata de conquistá-la, dominá-la. Essa linguagem se presta à elaboração não somente de uma técnica, mas de uma tecnologia, pois, além de transmitir procedimentos, ela os modifica conscientemente por uma busca calculada da melhor desempenho. A busca por uma eficácia cada vez maior se reflete nos métodos de organização do trabalho. A linguagem da racionalidade positiva, entretanto, apresenta suas limitações ${ }^{18}$. O escopo do nosso estudo é aprofundar essas limitações. Mas, por hora, é ainda necessário esboçar melhor o quadro geral da nossa discussão.

As principais características da sociedade moderna são: trabalho calculado em vista de uma eficácia progressivamente maior, linguagem da racionalidade científica, valores centrais do progresso e da utilidade; acrescente a esses elementos a presença de

4 KIRSCHER, 1992, p. $80-81$.

CANIVEZ, 1999, p.145-146.

DUBARLE, 1970, p. $527-528$.

DOUMIT, 1970, p. $514-515$.

8 CANIVEZ, 1999, p.146.

\begin{tabular}{|l|l|l|l|l|}
\hline Q Povista Dialectus & Ano 9 & n. 19 & Agosto-Dezembro 2020 & p. 38-50 \\
\hline
\end{tabular}


um mecanismo de troca e produção e um sistema de funções sociais hierarquizadas ${ }^{19}$. Como desempenha papel de destaque, importa frisar que a noção de mecanismo social pressupõe a noção mais fundamental de mecanismo geral, noção essa cara ao conceito de modernidade. O princípio da modernidade poderia ser anunciado da seguinte maneira: a realidade, seja ela qual for, é estruturada como um mecanismo. A noção de mecanismo e inicialmente imposta e edificada na elaboração das ciências matemáticas da natureza, sendo, em seguida aplicada pelas ciências sociais ao seu domínio particular, a sociedade É precisamente essa ideia de mecanismo que descortina a época moderna, de modo que a sociedade moderna, bem como a ciência com base na qual esta se percebe - as ciências sociais - são consequências daquele que é o evento fundacional da modernidade: sua ciência moderna ${ }^{20}$. O mecanismo social descrito e analisado por Weil corresponde ao sistema técnico-econômico da luta humana contra a natureza ${ }^{21}$.

Descartes é considerado um nome paradigmático para a ciência da modernidade, tendo em vista que na sua concepção de ciência, a técnica apresenta um papel de destaque, ciência e técnica estando intimamente interligadas ${ }^{22}$.

Essa vinculação é uma característica marcante da civilização moderna, em que a ciência se prolonga naturalmente nas suas aplicações técnicas. Descartes, enquanto fundador da filosofia moderna, situa-se também no início desse caráter tecnológico que o saber passou a ter na história do mundo moderno ${ }^{23}$.

\section{A ciência da condição.}

Nesse momento do nosso itinerário podemos trazer à lume o seguinte acréscimo: a ciência, a técnica e a linguagem da eficácia da sociedade moderna pertencem ao que no pensamento weiliano está sob a categoria ${ }^{24}$ da condição. Essa linguagem é

19 CANIVEZ, 1999, p.146-147.

KIRSCHER, 1992, p. 82.

DUBARLE, 1970, p. 527.

Conferir SILVA, 1993, p. 93 - 95.

SILVA, 1993, p. 94.

24 Um aparte sobre os termos categoria e atitude pode ser elucidativo para quem não está familiarizado com esses conceitos fundamentais da filosofia weiliana. Vamos a eles. Atitude. O indivíduo concreto vive na sua atitude e ela é o que ele vive, é a vida mesma do ser humano, aquilo que lhe parece como natural e que, justamente por sê-lo, não é necessariamente pensado por ele. O indivíduo pode seguir a vida na sua atitude sem querer compreendê-la num discurso. Mas, a partir do momento que ele o faz, captando o seu essencial, ele formula uma categoria (PERINE, 1987, p. 137). "Categoria deve ser entendida aqui como o conceito sob o qual se organiza e ganha sentido tudo aquilo que os homens fazem sob uma determinada atitude" (PERINE, 1987, p. 137). Na sua relação recíproca, categoria e atitude tratam, respectivamente, dos diferentes discursos possíveis, de um lado, que, por seu turno, dão conta das variadas formas de vida assumidas pelos homens na história, de outro (CAILLOIS, 1977, p. 1).

\begin{tabular}{|l|c|c|c|c|}
\hline Gevista Dialectus & Ano 9 & n. 19 & Agosto-Dezembro 2020 & p. 38-50 \\
\hline
\end{tabular}


formalmente a mesma em todas as sociedades modernas, o que constitui o chamado primeiro universal ao qual todo aquele que vive nessas sociedades deve ter acesso: a linguagem da ciência e da técnica do trabalho social. Entretanto, essa linguagem da eficácia da sociedade moderna não diz ao indivíduo o que fazer da sua liberdade. Aqui reside o núcleo do problema da eficácia técnica ${ }^{25}$. Contudo, antes de abordar essa dificuldade, é imperativo determinar melhor o que representa a categoria da condição.

Sabemos que o nosso mundo não é o mesmo da cidade antiga ou do medievo de vida pública e instituições dominadas pelo cristianismo. Esse mundo guardava uma relação diferente com a natureza, com o Estado, a política e o trabalho e não conhecia a noção de mecanismo tão cara aos modernos. O mundo moderno, por sua vez, se caracteriza pelo progresso e pela técnica, pela progressiva dominação das forças e recursos naturais. Para o mundo moderno, o trabalho eficaz é a atividade suprema. Na cidade antiga ocorria o contrário, com a observância da política como atividade preponderante e com a inferiorização do trabalho. $\mathrm{O}$ mundo moderno reinterpretou a linguagem antiga com o intuito de transformar a natureza, produzir e fabricar. Como consequência disso, a antiga concepção de ciência como discurso em consonância com uma realidade objetiva cuja finalidade é o contentamento na teoria, cede lugar a uma ciência de gênero novo, cuja finalidade é a dominação da natureza e que inaugura um discurso no qual termos como objeto, lei e natureza ganham outro significado. Esse discurso novo ${ }^{26}$, Weil descreve enquanto tipo ideal sob a categoria da condiçã $o^{27}$.

Sob essa categoria, a natureza é considerada como um sistema de condições: fenômenos que são condicionados uns pelos outros. O ser humano que existe aqui passa a refletir-se de acordo com esse sistema de condições, interpretando-se auxiliado por uma ciência matemática, física, biológica, sociológica, psicológica, etc. Esse arcabouço científico the permite conhecer a totalidade dos fatores objetivos aos quais ele se reduz. A ciência da condição atende a um projeto de progressiva dominação da natureza. Disso decorre o ideal do progresso, da técnica cada vez mais eficiente e da produção de bens

25 Conferir CANIVEZ, 1999, p.163 - 164.

26 Devemos ponderar que a condição, por si só, é insuficiente para definir toda a modernidade, mas a parcela da modernidade presente na condição (no conceito de mecanismo, a neutralidade axiológica) Weil encontra em Max Weber (KIRSCHER, 1992, p. 92 - 93). A condição ocupa o lugar de atitude característica da modernidade por ser a mais difundida e a mais natural, representando a consciência média difundida nesse período no homem da sociedade industrial (PERINE, 1987, p. 181). Entretanto, essa categoria é um aspecto necessário, mas não suficiente, de toda atitude moderna. Aqueles (cientistas, positivistas, pragmáticos) que a consideram como dimensão única da modernidade tomam como totalidade aquilo que é apenas um momento (KIRSCHER, 1992, p. 86 - 87).

27 CANIVEZ, 1999, p. 48.

\begin{tabular}{|l|c|c|c|c|}
\hline Qevista Dialectus & Ano 9 & n. 19 & Agosto - Dezembro 2020 & p. 38 - 50
\end{tabular}


cada vez mais sofisticados. Contudo, essa linguagem é incapaz de colocar adequadamente a questão sobre o sentido da dominação da natureza. Por não ser passível de ser formulada na linguagem da técnica, a compreensão do sentido do progresso carece aqui de todo aprofundamento. Tudo então não é mais que objeto da ciência da condição, incluindo os valores morais; metafísica e ontologia, por sua vez, tornam-se objetos de profundo ceticismo. Isso porque tudo aquilo que não se traduz na linguagem da racionalidade positiva e do cálculo, não é passível de ser posto e, portanto, considerado $^{28}$.

A linguagem da condição é a da ciência em progresso. Essa ciência é a do trabalho, a técnica, que é apenas instrumento para o conhecimento das condições ${ }^{29}$.

\footnotetext{
A linguagem se torna. Então, o pensamento técnico liberto de todo entrave. Não é a primeira vez que o trabalho e a técnica desempenham um papel; a diferença aqui é que eles já não desempenham, em verdade, um papel, mas formam a própria atitude. Não é possível atribuir-lhes um lugar, porque o sistema dos lugares é criado por ele ${ }^{30}$.
}

A linguagem do trabalho é tão importante na categoria da condição que a natureza, tanto exterior quanto interior, é determinada de acordo com o progresso do trabalho, sempre até segunda ordem. Substituindo a visão do cosmos antigo surge sobranceiro o projeto humano de dominar a natureza ${ }^{31}$. O método do qual esse projeto se vale é o da experiência visando o acúmulo de saber técnico para a ampliação desse mesmo saber. Não se trata aqui de uma ciência como aquela da teoria antiga, mas da elaboração de hipóteses úteis, cálculo das condições; o que importa, portanto não é compreender, mas agir com sucesso. Em uma palavra, o que interessa acima de qualquer coisa é a eficácia ${ }^{32}$.

A atitude da condição se opõe a qualquer busca pelo sentido, substituindo-a pelo enriquecimento científico e material. Isso se torna compreensível porque questões pessoais - preocupações morais, estéticas e religiosas, assim como as filosóficas, tidas como invenções de romancistas - são tomadas na conta de epifenômenos que devem apenas ser explicados em sua origem histórica para que sejam tratados e não reclamem nenhuma influência legítima sobre os trabalhadores ${ }^{33}$.

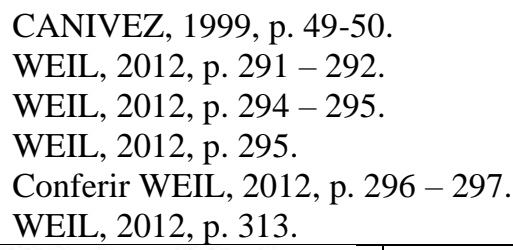


Assim, temos uma ciência moderna que é objetiva e prima pela eficácia técnica. Ela se orienta por um paradigma de dominação efetiva, pela força e sucesso de suas realizações, visando apoderar-se do mundo ${ }^{34}$. A idéia de natureza trazida pela ciência moderna é algo novo. Cosmos antigo e natureza moderna são duas interpretações, duas idéias, dois objetos de ciência radicalmente divergentes. Se a ciência antiga se interpreta como pura contemplação e investigação do princípio daquilo que é, a ciência moderna não concebe a natureza dessa perspectiva. A ciência moderna é ato constitutivo e investigativo do seu objeto ${ }^{35}$. A ciência contemplativa antiga não buscava interferir na ordem da natureza para subjugá-la, torná-la uma serva, um instrumento do qual a humanidade seria a mestra. Essa ciência desinteressada não procurava dominar, mas compreender. A ciência moderna descreve seu objeto em uma linguagem matemática que, para além de medidas e relações entre medidas, nada conhece. Não tem mais lugar aqui um cosmos, uma ordem teleológica, boa, justa, sensata, ou seja, não há mais espaço para qualquer qualidade não quantificável. Seu valor supremo é a eficácia ${ }^{36}$. E assim como a ciência moderna toma a natureza em um quadro condicionado de mecanismo, a sua contraparte, que é responsável pela autoconsciência da sociedade, procede de modo análogo. Temos então que a sociedade moderna aparece na condição como pseudo natureza, distinta da própria natureza, mas que é tão hostil e ameaçadora quanto a primeira $^{37}$. Dissemos que a responsável pelo modo como essa sociedade enxerga a si mesma é a ciência social. Passemos agora ao tratamento que a ciência social oferece à sociedade enquanto portadora do seu espelho.

\section{A compreensão do sentido.}

KIRSCHER, 1999, p. $148-149$.

35 Para tornar esse ponto mais claro, tomemos como exemplo a ciência do Estado de Hobbes, derivada fortemente das concepções modernas de ciência, cujo alicerce é o caráter assertórico das matemáticas. "No tempo de Hobbes, o método para as ciências estava nas matemáticas. Os teoremas da geometria, por exemplo, não dependem em nada da observação empírica para serem verdadeiros. Quando dependemos da experiência, estamos sempre sujeitos ao engano. Mas, se nos limitamos a deduzir propriedades de figuras ideais, não há risco de erro. E isso, antes de mais nada, porque as figuras geométricas não resultam da observação (não existe, na natureza, círculo ou triângulo perfeito...), mas são criação da nossa mente. Em suma: só podemos conhecer, adequada e cientificamente, aquilo que nós mesmos engendramos" (RIBEIRO, 2001, p. 76).

36 KIRSCHER, 1992, p. 83 - 85.

37 PERINE, 1987, p. 181.

Ano 9

ก. 19

Agosto - Dezembro 2020

p. $38-50$ 
Sabemos que a condição é a categoria filosófica da sociedade moderna e das ciências sociais $^{38}$. O surgimento das ciências sociais, a frente das quais estão a sociologia e a economia política, está relacionado com a própria consciência de si da sociedade moderna. $\mathrm{O}$ fato de destaque dessa autoconsciência é o caráter exclusivo da organização do trabalho social, ou seja, a maneira como se dá a luta contra a violência primeira ${ }^{39}$. A análise científica da sociologia não exclui a consideração pelo detalhe, mas prima pelos conceitos extraídos de uma análise macroscópica ${ }^{40}$. Essa consciência de si que as ciências sociais proporcionam à sociedade moderna é marcada pelos seguintes traços: é positiva, abstrata e redutora, por natureza essencialmente cientificista, que não reconhece nenhuma realidade além do mecanismo social ${ }^{41}$. Essa perspectiva encerra uma limitação estrutural quanto às capacidades para lidar com questões que fogem do escopo da técnica, do mecanismo, da eficácia. Assim sendo, podemos oferecer como situação-exemplo que no caso da política, os problemas postos e, em princípio, respondidos pela racionalidade que caracteriza fundamentalmente a sociedade moderna, são os problemas técnicos da política. Já o problema da política só pode ser compreendido quando corretamente posto como problema da ação razoável, ou seja, filosoficamente ${ }^{42}$. Isso significa que, embora as pesquisas positivas das ciências sociais sejam ferramentas imprescindíveis para indicar as condições necessárias para a ação humana, elas apresentam limitações, pois são incapazes de apreender o sentido da ação. O inventário de fatos e condições empreendido pelas ciências sociais só terá um sentido em vistas à ação humana. As pesquisas das ciências sociais, na medida em que são objetivas, não têm como distinguir o problema essencial dentre aqueles que lhe chegam ${ }^{43}$.

Do que se trata, então, esse problema da ação? Caso se considere que o ser humano vive em um mundo, não em meio a correntes de elétrons, que a humanidade é dotada de sentimentos e pensamentos, não sendo simples objetos da psicologia, fisiologia, da economia política e ciências sociais, a questão do sentido aparece claramente quando antes estava oculta, tão logo se reconheça que o ente humano nasce violento e pode continuar a sê-lo. A saída para a questão do sentido passa por uma análise da ação e dos discursos do homem que revelam o que é o mundo e que ele pode ser para ele mesmo.

$\begin{array}{ll}38 & \text { KIRSCHER, 1992, p. } 86 . \\ 39 & \text { KIRSCHER, 1992, p. } 80 . \\ 40 & \text { WEIL, 1991, p. 256. } \\ 41 & \text { KIRSCHER, 1992, p. } 81-82 . \\ 42 & \text { PERINE, 1987, p. 87. } \\ 43 & \text { DOUMIT, 1970, p. } 511-512 .\end{array}$ 
Daniel Benevides Soares

Trata-se de uma análise compreensiva da compreensão, que não é científica, mas da ordem da filosofia ${ }^{44}$. Indicar o que seja uma compreensão da compreensão é uma tarefa eminentemente filosófica.

Para Weil, filosofia é a compreensão daquilo que é fundamental. Esse fundamental encontra-se não em objetos absolutos ou relativos, mas nas decisões da liberdade humana que conferem sentido ao mundo ${ }^{45}$. A filosofia ainda que se apresente sob o paradigma hipotético-dedutivo não opera como o fazer do cientista, para o qual todo problema só pode aparecer no interior do seu sistema hipotético-dedutivo, mas se reporta sempre a uma realidade que deve ser a realidade humana. A filosofia não é uma ciência no sentido das ciências da observação e da experimentação. Não obstante, a filosofia é científica, isso significando que a filosofia é coerente ${ }^{46}$.

No reino das condições, a questão do sentido perde a importância, bem como toda reflexão que não serve ao progresso do trabalho. Conforme apontamos, isso se dá porque natureza aqui não é mais cosmos, mas sim o que condiciona o homem e é condicionada por ele. O que existe é a luta contra essa natureza com o único objetivo de satisfazer necessidades e desejos que são parte ou derivados dessa natureza, necessidades e desejos que são apenas condições condicionadas. Para o indivíduo que vive na atitude da condição, termos como felicidade e salvação só são tomados na perspectiva da pergunta pelas condições que possibilitaram o surgimento dessas idéias ${ }^{47}$. Não se trata de evocar uma nostalgia que remonte a esse passado como uma forma de reintroduzi-lo na História; muita coisa de terrível no plano político já se fez tendo como ingrediente do seu caldeirão de venenos esse apelo irracional e não-razoável ${ }^{48}$. Trata-se apenas de, resguardando a importância e as conquistas da ciência moderna e da sua eficácia técnica, não perder de vista que o ser humano permanece humano na sua pergunta constitutiva pelo sentido.

\section{Considerações finais.}

Distinguindo-se de um estudo científico, a questão do sentido é por excelência uma questão filosófica. Ela não pode, portanto, ser respondida nem pelas modernas

\footnotetext{
44 WEIL, 1970, p. 295 - 296.

45 KIRSCHER, 1999, p. 152.

46 WEIL, 1970 , p. $357-358$.

47 WEIL, 2012, p. $290-291$.

48 Conferir a esse respeito STANLEY, 2019, p. $19-36$.
}

\begin{tabular}{|l|c|c|c|c|}
\hline Qenista Dialectus & Ano 9 & n. 19 & Agosto-Dezembro 2020 & p. 38-50 \\
\hline
\end{tabular}


ciências da natureza, ciências da condição, nem por aquelas que lhe são análogas, como as ciências sociais, como a economia política. Desse modo, compreende-se que A racionalidade inerente à modernidade, portanto, técnica e atrelada ao mundo da condição, se distingue da razão que comporta a pergunta pelo sentido ${ }^{49}$. Não é do escopo da ciência que produz a bomba a pergunta se ela deve ou não ser lançada, mas apenas como construíla da maneira mais eficaz, "eficaz" nesse caso significando "mais destrutiva".

A partir dessa constatação, podemos cair em duas tentações distintas, mas igualmente fáceis no seu antagonismo. Uma, é simplesmente não resistir e jogar o jogo da modernidade sem concessões, aceitando sua racionalidade estritamente técnica e as consequências que vêm com ela - sejam elas quais forem. Outra, é a recusa completa dessa racionalidade em nome de uma nostalgia de tempos que, supostamente, eram melhores. Weil, por sua vez, não defende nenhuma. Se por um lado não é possível para o indivíduo moderno abrir mão das conquistas da racionalidade técnica, por outro, não é razoável $^{50}$ ignorar as possibilidades de violência que a seguem de perto. As posições extremas, para Weil, são apenas obstáculos para que se coloque adequadamente o problema do sentido. Pensar o mundo significa ter tanto um discurso teórico como um prático, levando-se em conta sempre que existe uma distinção entre o ser e o dever ser: o mundo não está finalizado, mas sempre em curso de realização. O mundo, assim, tornase o problema sobre o qual se debruça a ação. Trata-se de uma orientação filosófica. $\mathrm{O}$ filósofo põe o duplo aspecto do problema. Tem-se a inolvidável utilidade da ciência e técnica modernas. Existem consequências negativas em negligenciar o conhecimento da realidade conforme apresentado pelas ciências positivas, conhecimento esse que permite transformá-la. Devemos, entretanto, reconhecer a enorme e perigosa violência que é desencadeada a partir da revolta, do desespero resultantes do sentimento da perda do sentido. Trata-se, em suma, não apenas de conhecer a realidade, mas também de pensar o mundo ${ }^{51}$.

Para concluir, queremos citar um trecho do conto Enfermaria $n^{\circ} 6$ em que um personagem, o médico Andriéi Iefímitch, reflete amargamente sobre a necessidade do

49 KIRSCHER, 1992, p. 275 - 276.

50 Embora as definições de racional e razoável possam parecer confusas em uma primeira visada, um caminho mais seguro de dar tais definições seria a via negativa, ao dizer o que um ser razoável não é. Seguindo essa metodologia, ser razoável, por exemplo, não é a qualidade de uma coisa, de um objeto com o qual o homem se depara no mundo. Razão, indo adiante, não é descrita de fora, mas descreve a si mesma, põe a si mesma em movimento, e é sujeito na medida em que separa a si mesma daquilo que é objeto apenas em oposição a si. A razão aparece assim como um processo de autocriação que conhece a si mesmo por meio de oposições. Existe um aspecto dialético na razão (KLUBACK, 1987, p. 133).

51 KIRSCHER, 1992, p. $276-278$.

\begin{tabular}{|l|c|c|c|c|}
\hline Q Rovista Dialectus & Ano 9 & n. 19 & Agosto-Dezembro 2020 & p. 38-50 \\
\hline
\end{tabular}


sofrimento, como uma forma de justificar para si mesmo sua inação diante dos tormentos que encontra no hospital pelo qual passa a ser responsável e cuja falta de coragem moral não lhe permite vencer os vícios ali instalados:

\begin{abstract}
Em primeiro lugar, dizem que os sofrimentos conduzem o homem à perfeição e, em segundo, se a humanidade aprender realmente a aliviar os seus sofrimentos por meios de gotas e pílulas, há de abandonar completamente a religião e a filosofia, nas quais até agora encontrou não só uma defesa contra todas as desgraças, mas até felicidade ${ }^{52}$.
\end{abstract}

Esse rastro de modorra, que sai da mente do personagem como autoindulgência e absolvição moral de graça própria para o seu quietismo, não é verdadeira. A filosofia é atividade inerente ao humano. Prescindir da filosofia significa superar a condição humana. Chegado o dia em que de fato a ciência da condição resolva todos os casos de dores por meio de pílulas, ela resolve também a situação humana. Vencer todas as dores a que o corpo está sujeito por meio das doenças não significa vencer a sujeição em potência aos demais males naturais e ao mal radical ${ }^{53}$. Enquanto houver humanidade, há violência. Ela é uma das duas possibilidades humanas irredutíveis, a que se realiza primeiro e que motiva a outra que lhe vem como resposta: a filosofia. Enquanto existir humanidade, há violência e há também a pergunta pelo sentido, pulsando sob todo o progresso técnico da ciência, ainda que ignorada.

\title{
REFERÊNCIAS:
}

CAILlOIS, R., Politique et violence chez Eric Weil. Revue de l'enseignement de philosophie, $28^{\circ}$ année, $\mathrm{n}^{\circ}$ 5, p. 1 - 10. Paris, 1977.

La violence pure est-elle démoniaque? In.: Actualité d'Éric Weil, Paris: Éditions Beauchesne, 1984, p. 213 - 222.

CANIVEZ, P. Weil. Paris: Socié te d'édition les Belles Lettres, 1999.

DOUMIT, E. Etat et société modernes dans la 'Philosophie politique'. Archives de Philosophie, ${ }^{\circ}$ 33, p. 511 - 526. Paris: Beauchesne, 1970.

DUBARLE, D., Totalisation terrestre et devenir humain. Archives de Philosophie, $\mathrm{n}^{\circ}$ 33, p. 527 - 545. Paris: Beauchesne, 1970.

52 TCHEKOV, 1995, p. 243.

53 Sobre o conceito de mal radical em Weil, observar 2011, p. 55 - 56

\begin{tabular}{|c|c|c|c|c|}
\hline Rovita Aialectus & Ano 9 & n. 19 & Agosto - Dezembro 2020 & p. $38-50$ \\
\hline
\end{tabular}


KIRSCHER, G. Figures de la violence et de la modernité: Essais sur la philosophie d'Eric Weil. Lille: Presses Universitaires de Lille, 1992.

KIRSCHER, G. Eric Weil ou la raison de la philosophie. Paris: Presses Universitaires du Septentrion, 1999.

KLUBACK, W. The idea of humanity. Boston, University Press of America, 1987.

PERINE, M. Filosofia e violência: sentido e intenção da filosofia de Éric Weil. São Paulo, Edições Loyola, 1987.

RIBEIRO, R. J. Hobbes: o medo e a esperança. In: Clássicos da política, Francisco Welfort (org.). São Paulo: Editora Ática, 2001.

SILVA, F. L. Descartes: a metafísica da modernidade. São Paulo: Moderna, 1993.

STANLEY, J. Como funciona o fascismo: a política do "nós" e "eles". Porto Alegre: L\&PM Editora, 2019.

TCHEKOV, A. As três irmãs/contos. São Paulo: Abril Cultural, 1995.

WEIL, E. Lógica da filosofia. São Paulo: É realizações, 2012 A.

WEIL, E. Filosofia política. São Paulo: Edições Loyola, 2011 A.

WEIL, E. La philosophie est-elle scientifíque? Archives de Philosophie, $n^{\circ} 33$, p. 353 369. Paris: Beauchesne, 1970.

WEIL, E. La culture. Philosophie et réalité II. Paris, Beauchesne Éditeur, 2003.

\begin{tabular}{|l|l|l|l|l|}
\hline Q Rovista Dialectus & Ano 9 & n. 19 & Agosto - Dezembro 2020 & p. 38-50 \\
\hline
\end{tabular}

